\title{
Medical Principles and Practice
}

Med Princ Pract 2010;19:499

DOI: $\underline{10.1159 / 000320313}$

\section{Contralateral Subdural Effusion Secondary to Decompressive Craniectomy: Differences in Patients with Large Hemispheric Infarctions and Traumatic Brain Injury}

\author{
Cumhur Kilincer, Mustafa Kemal Hamamcioglu \\ Department of Neurosurgery, Medical Faculty, Trakya \\ University, Edirne, Turkey
}

We have read with great interest the recent article by Yang et al. [1]. The authors analyzed the data of 169 patients who underwent decompressive craniectomy after head trauma and found that $11(6.5 \%)$ had contralateral subdural effusion. They also reported that clinical deterioration attributable to subdural effusion was seen in 8 of 11 cases. In 7 patients, effusion resolved spontaneously and 4 patients required surgery. They concluded that postoperative contralateral subdural effusion was not an uncommon complication.

In our clinic, we frequently perform decompressive craniectomy for uncontrolled brain edema caused by large hemispheric infarctions [2]. In most cases, we observe that an ipsilateral to contralateral midline shift somehow persists in the initial weeks after the procedure, even though satisfactory external decompression was achieved. Thus, following decompressive craniectomy, a contralateral subdural effusion and a subsequent contralateral to ipsilateral midline shift (i.e. reversal of shift) is an interesting phenomenon. In fact, this complication is extremely rare among stroke patients. We noted this event only once [3]. To our knowledge, that case is still a unique example of contralateral effusion associated with decompressive craniectomy after large hemispheric infarction.

So, what is the reason for the high incidence of contralateral effusion in the study by Yang et al. [1]? It may be explained by the fact that those patients had head trauma, a situation which is already prone to subdural effusion. Shrinkage of the swelled brain, a torn arachnoid layer due to trauma and existence of subarachnoid hemorrhage all may contribute to the development of subdural effusion after severe head trauma. In fact, an incidence of $7-12 \%$ of posttraumatic subdural effusion has been reported in patients with head trauma [4]. Craniotomy is also a well-known reason for subdural effusion. In fact, in another paper, Yang et al. [5] present valuable data showing how frequent subdural effusion occurs when these two conditions (i.e. head trauma and decompressive craniotomy) are combined. In that series, 23 of their 108 (21.3\%) patients developed subdural effusion after decompressive craniectomy for head trauma. Their data also showed that there was no preference regarding the location of the subdural effusion: it was ipsilateral to craniectomy in 11 cases, contralateral to craniectomy in 9 cases, and bilateral in 3 cases.

Yang et al. discuss the possible mechanisms responsible for the development of contralateral subdural effusion and stress the importance of the possible pressure gradient between the two hemispheres due to one-sided cranial vault expansion, disturbance in cerebrospinal fluid circulation and absorption, and shrinkage of the ipsilateral brain due to intraoperative tissue retraction. Given that subdural effusion is a potential complication of both head trauma and craniotomy, with no location preference (may also be ipsilateral), we believe that existence of the contralateral subdural effusion in those patients requires no further explanation. In our opinion, the development of contralateral effusion after decompressive craniotomy in patients with head trauma and its development in patients with large hemispheric infarction are completely different stories: while it is an extremely rare occurrence in ischemic stroke patients, it is a very likely complication in trauma cases since both head trauma and craniotomy predispose to this situation.

\section{References}

-1 Yang XF, Wen L, Li G, Zhan RY, Ma L, Liu WG: Contralateral subdural effusion secondary to decompressive craniectomy performed in patients with severe traumatic brain injury: incidence, clinical presentations, treatment and outcome. Med Princ Pract 2009;18:16-20.

-2 Kilincer C, Asil T, Utku U, Hamamcioglu MK, Turgut N, Hicdonmez T, Simsek O, Ekuklu G, Cobanoglu S: Factors affecting the outcome of decompressive craniectomy for large hemispheric infarctions: a prospective cohort study. Acta Neurochir (Wien) 2005;147:587-594.

-3 Kilincer C, Simsek O, Hamamcioglu MK, Hicdonmez T, Cobanoglu S: Contralateral subdural effusion after aneurysm surgery and decompressive craniectomy: case report and review of the literature. Clin Neurol Neurosurg 2005; 107:412-416.

4 Stone JL, Lang RG, Sugar O, Moody RA: Traumatic subdural hygroma. Neurosurgery 1981;8:542-550.

5 Yang XF, Wen L, Shen F, Li G, Lou R, Liu WG, Zhan RY: Surgical complications secondary to decompressive craniectomy in patients with a head injury: a series of 108 consecutive cases. Acta Neurochir (Wien) 2008;150:1241-1247.

Assoc. Prof. Dr. Cumhur Kilincer

Department of Neurosurgery

Medical Faculty, Trakya University

TR-22030 Edirne (Turkey)

Tel. +90 284235 5798, E-Mail ckilincer@yahoo.com

\section{KARGER}

Fax +4161306 1234

E-Mail karger@karger.ch

www.karger.com
C) 2010 S. Karger AG, Basel

$1011-7571 / 10 / 0196-0499 \$ 26.00 / 0$

Accessible online at:

www.karger.com/mpp 